\title{
Evolutionary phenome-genome analysis of cranial suture closure in mammals
}

\author{
Borja Esteve-Altava $^{1}$, Fabio Barteri ${ }^{1}$, Xavier Farré ${ }^{1}$, Gerard Muntané ${ }^{1,2}$, Juan Francisco \\ Pastor $^{3}$, Arcadi Navarro ${ }^{1,4,5,6}$
}

1. Institute of Evolutionary Biology (UPF-CSIC), Department of Experimental and Health Sciences, Pompeu Fabra University, Barcelona Biomedical Research Park, Carrer del Dr. Aiguader 88, 08003 Barcelona, Spain.

2. Hospital Universitari Institut Pere Mata, IISPV, Universitat Rovira i Virgili, Biomedical Network Research Center on Mental Health (CIBERSAM), 43206 Reus, Spain.

3. Museum of Anatomy, Department of Human Anatomy, University of Valladolid, 47002

Valladolid, Spain.

4. Catalan Institution of Research and Advanced Studies (ICREA), Passeig de Lluís Companys 23, 08010 Barcelona, Spain

5. CRG, Centre for Genomic Regulation, Barcelona Institute of Science and Technology (BIST), Carrer del Dr. Aiguader 88, 08003 Barcelona, Spain.

6. Barcelonaßeta Brain Research Center (BBRC), Pasqual Maragall Foundation, Wellington 30, 08005, Barcelona, Spain.

* corresponding author: Institute of Evolutionary Biology (UPF-CSIC), Department of Experimental and Health Sciences, Pompeu Fabra University, Barcelona Biomedical Research Park, Carrer del Dr. Aiguader 88, 08003 Barcelona, Spain. 


\section{ABSTRACT}

2

3 Cranial sutures are growth and stress diffusion sites that connect the bones protecting the brain. The

4 closure of cranial suture is a key feature of mammalian late development and evolution, which can

5 also lead to head malformations when it occurs prematurely (craniosynostosis). To unveil the

6 phenotypic and genetic causes of suture closure in evolution, we examined 48 mammalian species

7 searching for (i) causal links between suture patency, brain size, and diet using phylogenetic path

8 analysis; and (ii) instances of genome-phenome convergence amino acid substitutions. Here we

9 show that brain size and the anteroposterior order of ossification of the skull are the two main

10 causes of sutures patency in evolution. We also identified three novel candidate genes for suture

11 closure in evolution (HRNR, KIAA1549, and TTN), which have never been reported in clinical

12 studies of craniosynostosis. Our results suggest that different genetic pathways underlie cranial

13 suture closure in evolution and disease.

14

15 Keywords: Evolution; Anatomy; Brain Size; Craniosynostosis; Phylogenetic Path Analysis; 


\section{INTRODUCTION}

20 Cranial sutures separate the bones of the skull and function as sites of bone growth and stress

21 diffusion (Herring, 2008; Opperman, 2000). They are necessary to develop a healthy, functioning

22 head in mammals. Interestingly, while many sutures remain open through life, some cranial sutures

23 will naturally close by turning into bone. The closure of suture is a key feature of the mammalian

24 skull late development (Figure 1), growth, functioning, and evolution (Cray et al., 2014; Oh et al.,

25 2017; Roston \& Roth, 2019). However, a premature closure of sutures (craniosynostosis) can also

26 lead to head malformations in newborns (Cohen \& MacLean, 2000).

In mammals, cranial sutures closure evolves in coordination with the rest of the body. In fact, suture closure is positively correlated with skull size and body size (Bärmann \& Sánchez-Villagra, 2012;

Wilson \& Sánchez $\square$ Villagra, 2009). Cranial sutures and the brain are also tightly integrated by

31 physical contiguity and shared signaling pathways during development (Lieberman, 2010;

Richtsmeier \& Flaherty, 2013). Thus, changes of brain size could affect suture closure in evolution.

Likewise, diet can cause suture closure as a secondary effect of the mechanical loads generated no studies on the impact of these phenotypic traits to suture closure in evolution.

41 Anatomical constraints can also bias which sutures close and which remain open (Moss, 1975;

42 Lieberman, 2011; Esteve-Altava \& Rasskin-Gutman, 2014; Rasskin-Gutman \& Esteve-Altava,

43 2018). Theoretical models predict that the whole arrangement of sutures in the skull—as a

44 network-acts itself as an anatomical constraint that influences which sutures will close and which 
ones will remain open (Esteve-Altava et al., 2017), for example, by directing the signaling pathways that promote osteogenesis through mechanosensors (Khonsari et al., 2013; Katsianou et al., 2016). Additionally, the timing of ossification of skull bones, from face to vault (Koyabu et al., 2014), and of suture closure, from vault to face (Rager et al., 2014), have also the potential to explain biases in suture closure, since one suture closure may influence the closure of a neighboring suture.

The genetic causes of suture closure in evolution remain largely unknown. Most of our knowledge comes from medical studies of genetic syndromes causing premature suture closure in humans (Lattanzi et al., 2017; Morriss-Kay \& Wilkie, 2005; Poot, 2019; Twigg \& Wilkie, 2015; Wilkie et al., 2017) and animal models (Cornille et al., 2019; Grova et al., 2012). These studies have revealed a complex network of genes involving many signaling pathways (e.g., $B M P / T G F-\beta, F G F$, and WNT). However, about $80 \%$ of craniosynostosis cases are nonsyndromic: they typically affect only one suture and are not associated with other body malformations (Dempsey et al., 2019; Garza \& Khosla, 2012). There is little information on the genetic causes of nonsyndromic craniosynostosis (Sewda et al., 2019). Evolutionary genomics offers a powerful tool to explore the genetic causes of natural variation (Alföldi \& Lindblad-Toh, 2013; de Magalhães \& Wang, 2019; Smith et al., 2020), as shown by studies on skull shape evolution (Roosenboom et al., 2018) and marine adaptations (Foote et al., 2015; Zhou et al., 2015). Evolutionary studies have shown that some of the genes regulating suture closure (e.g., $B M P 3, M S X 2, R U N X 2$ ) have evolved under positive selection in humans and other primates (Green et al., 2010; Magherini et al., 2015; Twigg et al., 2015; Wu et al., 2010, 2012), which suggests that the same processes favoring suture closure at evolutionary scale could be causing craniosynostosis conditions. Similarities of potential genetic factors and phenotypes between skull evolution and craniosynostosis (e.g., fewer bones, same sutures frequently affected, related shape changes) could indicate that analogous mechanisms underlie suture closure in evolution and disease (Esteve-Altava et al., 2017; Richtsmeier, 2018; Richtsmeier et al., 2006). 
72 Here we assessed the evolutionary factors determining the closure of the metopic, coronal, and

73 sagittal suture in mammals. To this end, we analyzed the cranial anatomy of 48 species of

74 mammals, for which their reference genomes were aligned at UCSC (100-way) and for which there

75 was information on their diet and brain mass in the literature. First, we tested 12 alternative

76 evolutionary hypotheses of how brain size, diet, and developmental constraints may determine

77 suture closure in evolution. Then, we looked for convergent amino acid substitutions in multiple-

78 sequence alignments of proteins, comparing species with sutures closed or open. Our hypotheses

79 are that (1) brain size, diet hardness, and constraints, together, determine suture patency and closure

80 in evolution; (2) species with a given suture closed will share mutations in the same key genes that

81 will be absent in closely related species with the same suture open; (3) these genes will be enriched

82 in biological functions relevant to cranial suture formation and maintenance, brain growth, and

83 biomechanical performance; and (4) they will overlap with genes previously associated to

84 craniosynostosis in clinical studies.

85 


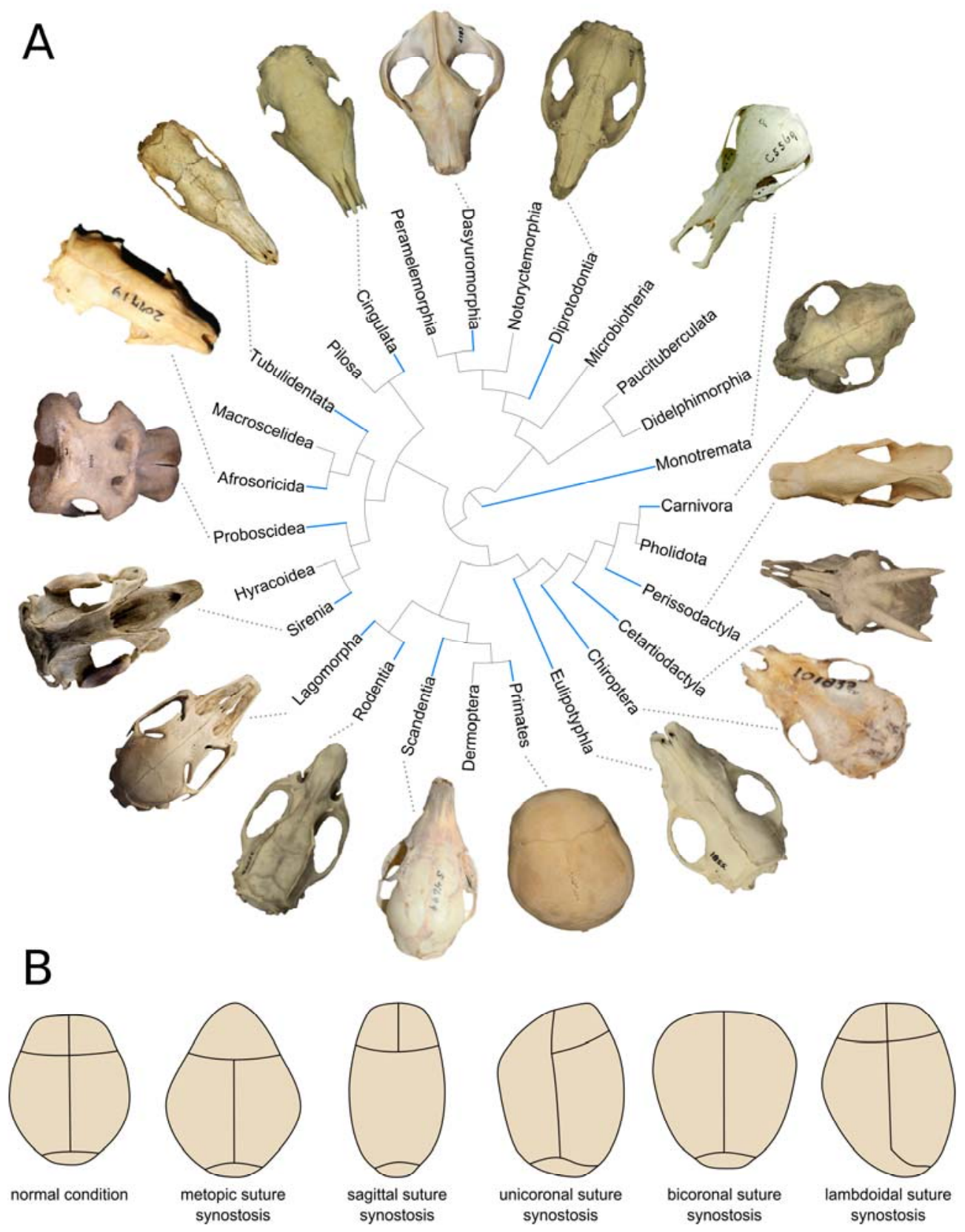

Figure 1. Cranial suture close in evolution and disease. (A) Mammalian orders studied (blue lines), with representative skulls in dorsal view showing the differences in patency for the metopic, coronal, and sagittal sutures. Some mammals close their cranial sutures after birth, and we see them closed in adults, while others keep their sutures open through life or until an old age. (B) Outlines showing the consequences in the shape of the skull by a premature suture closure in humans, a condition called craniosynostosis. 


\section{RESULTS}

The patency of the metopic, coronal, and sagittal sutures varied in the sample set of mammals analyzed, with some taxonomic groups showing a consistent pattern of closure for some sutures (Figure 2). We used the frequency of suture patency (i.e., specimens with the suture open/total specimens) to infer the causal links between suture closure and other phenotypic traits of interest in a phylogenetic path analysis. The high degree of conservation of suture patency within species enabled us to categorize sutures phenotype, as either open or closed, and to carry out a search for convergent amino acid substitutions in the protein-coding genes.

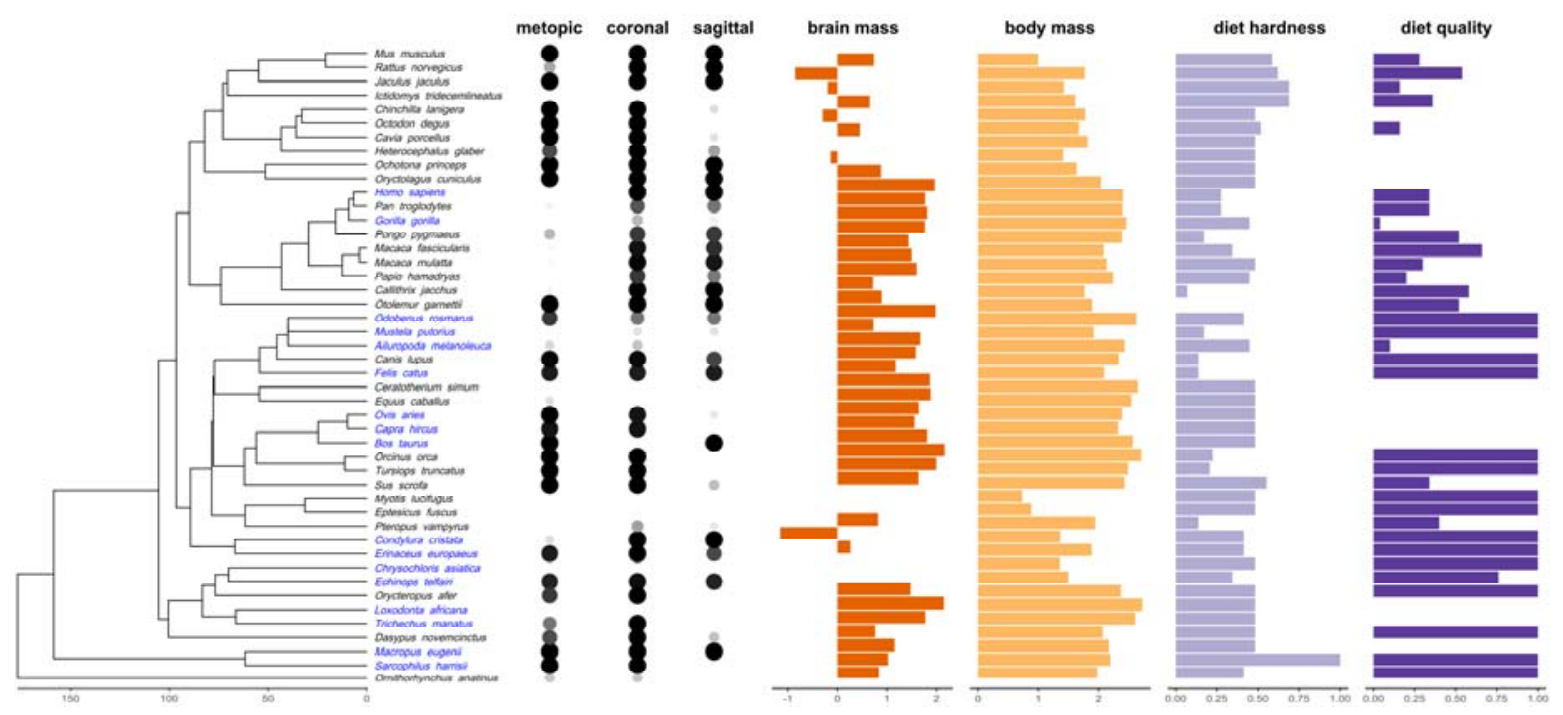

Figure 2. Variation in suture patency and potentially related traits in mammals. In blue, species used for the pair-wise convergent amino acid substation analysis. Note that different pairs of species were used for each suture and that only suture patency below/above the threshold of $0.25 / 0.75$ were considered. Dot size and gray scale of suture patency ranges between 0 to 1 , corresponding to $0 \%$ to $100 \%$ of specimens with the suture open in our sample. Brain and body mass shown as log-transformation of weight in grams. Diet hardness and quality are normalized. See Supplementary File 1 for the exact values of each variable. 


\section{Suture patency and life-history traits evolution}

97 The best supported model for the patency of the metopic, coronal, and sagittal sutures in evolution

98 agrees with the hypothesis of an anteroposterior direction in sutures' closure following the timing of

99 skull ossification and with the influence of brain size after correcting for body size $(\mathrm{CICc}=56.9, p$ -

100 value $=0.196, w=0.829)$. (N/A: CICc is a modified version of AICc for path analysis, significant

101 p-values, < 0.05, mean that the model is rejected, see Methods). Figure 3 summarizes the results of

102 the phylogenetic path analysis. The best model includes mid-to-high effects of one suture on

103 another in an anteroposterior direction and low-to-mid effects of brain size on sutures. Larger brains

104 (after correcting for body size) tend to favor the maintenance of the coronal and sagittal sutures

105 open, and to a lesser extent, the closure of the metopic. In contrast, diet quality has a negligible

A

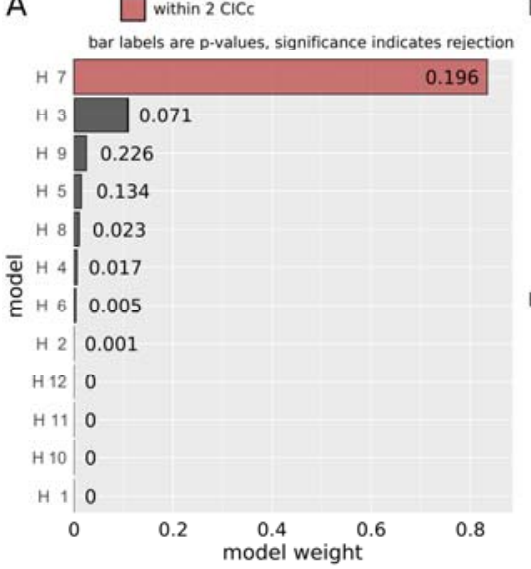

B

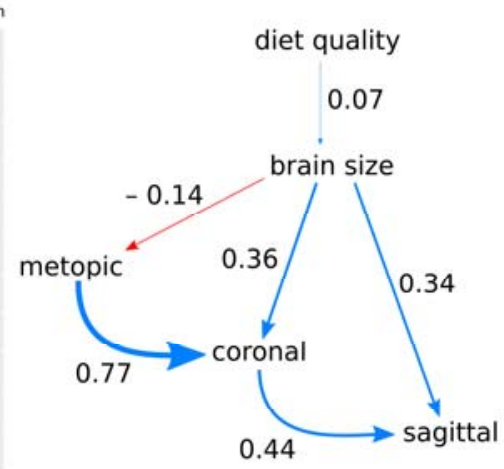

C

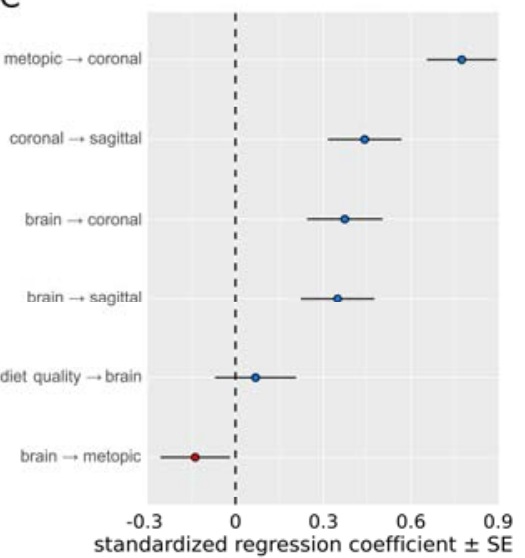

Figure 3. Summary of the phylogenetic path analysis. (A) Comparison of statistics for each model. There is only one best supported causal model (i.e., within 2 CICc and p-value $>0.05$ ). (B) The best model shows a causal relation for cranial sutures patency following an anteroposterior direction, with larger brain sizes causing the sutures coronal and sagittal to remain open and the metopic suture to close at an evolutionary scale. An arrow indicates the direction of the causal 
relation, its width corresponds to the standardized regression coefficient (i.e., how much the causal variable affects the effect variable), and its color represents a positive (blue) or a negative (red) effect. (C) Amount of change (with standard error) produced by causal variables on effect variables for the best supported model.

\section{Convergent amino acid substitutions in species with cranial sutures closed}

111 We compared the amino acid sequences of 10,922 genes in pairs of closely related species that vary

112 in their suture patency (open versus closed). We recovered an aggregate of 6,158 putatively

113 convergent amino acid substitutions (CAAS) in 3,250 unique genes. These genes were mutated in at 114 least one suture, meaning that they were identified in three pair-wise comparisons of closely related 115 species with different suture patency. The number of unique genes found is significantly lower than 116 expected at random (1,000-bootstrap: $\alpha_{0.05}=5,759.8$; see Methods for more details). We recovered a total of 28 candidate genes that overlap in the three sutures (i.e., identified in nine pair-wise comparisons), which were used to perform set enrichment analyses. This is a significant overlap between the genes identified for each suture compared to that expected if the three sets were independent (Fold Enrichment $=15$, p-value $=5.04 \mathrm{E}-25)$. Out of the 28 candidates, three genes

121 were also internally validated in the whole sample of mammals: Hornenin (HRNR), KIAA1549, and

122 Titin $(T T N)$. We focused our discussion on these three gene and their potential role in suture

123 closure. See Supplementary File 1 for the complete list of CAAS.

\section{Functional and pathological enrichment}

126 Only one GO functional enrichment was found for the list of 28 candidate genes shared between the 127 three sutures: a molecular function related to limpid transport $(\mathrm{GO}: 0005319, \mathrm{ER}=20.97, \mathrm{FDR}=$ 128 0.013). For comparison, we also performed functional enrichment analyses for genes identified in at 129 least two sutures (i.e., found in six pair-wise comparisons). This shows that other well supported GO enrichments for these genes include, for example, biological adhesion (GO:0022610, ER = 
$1312.39, \mathrm{FDR}=0.005)$ and components of the extracellular matrix $(\mathrm{GO}: 0031012, \mathrm{ER}=2.47, \mathrm{FDR}=$

132 0.006). See more details in Supplementary File 1. Overall, these results provide little support to

133 our initial working hypothesis that candidate genes would be enriched in functions commonly

134 associated with suture biology.

136 Moreover, neither of the 28 candidate genes overlaps with craniosynostosis genes as ascertained

137 from the study of human disease. None of the candidate genes is present in the lists of genes from

138 the literature (set 1), from upregulated in nonsyndromic craniosynostosis osteoblast cultures (set 2),

139 or from GWAS of nonsyndromic metopic and sagittal cases (set 3). As a reference, we also

140 estimated the overlap between these three gene sets. One-sided Fisher's exact tests show that only

141 one overlap for the list of literature genes and the list of GWAS (set 1 vs set 2: Odds Ratio $=1.616$,

142 FDR $=0.106$; set 1 vs set 3: Odds Ratio $=93.29$, FDR $=2.05 E-30$; set 2 vs set $3:$ Odds Ratio $=$

$1431.08, \mathrm{FDR}=0.807)$. In contrast to candidate genes, genes associated to human craniosynostosis are

144 enriched in biological functions more related to suture biology (see Supplementary File 1). This

145 result rejects our starting hypothesis that candidate genes, with mutations linked to suture closure in 146 evolution, would overlap with genes associated to craniosynostosis. 


\section{DISCUSSION}

149 Our results suggest that cranial suture closure in evolution is regulated by two developmental

150 processes: the order of ossification of skull bones and the growth of the brain relative to body size.

151 In contrast, we found no support for diet hardness (as a proxy for chewing biomechanics) as a cause

152 for differences in suture patency among species. From a genetic point of view, we identified 28

153 candidate genes for suture closure in evolution, out of which three show the strongest support:

$154 H R N R$, KIAA1549, and TTN. These genes have never been causally linked to craniofacial

155 development, suture biology, or craniosynostosis. However, they are expressed in tissues adjacent

156 to cranial sutures, such as the brain and skeletal muscles, which affect suture biology.

\section{Brain size and ossification timing determine suture patency in evolution}

Brain growth is tightly integrated with cranial suture maintenance and closure in normal

Richtsmeier \& Flaherty, 2013). The traditional idea is that suture closure is a passive consequence

of the growth of the brain (Moss \& Young, 1960; Moss, 1975), with dura mater triggering a

(Opperman, 2000; Spector et al., 2002). Our results support a direct influence of brain size on suture way to brain size is unclear, but it could be a consequence of how the growing brain interacts

169 differently with each of the enclosing bones and sutures (Barbeito-Andrés et al., 2020).

171 Our evolutionary analysis shows that the patency of a suture depends also on the patency of other

172 sutures, following the most common anteroposterior order of ossification of the skull in mammals

173 (Koyabu et al., 2011, 2014). This result agrees with recent theoretical findings proposing that the 
174 organization of the skull, as a network of bones connected by sutures, can bias suture closure

175 (Esteve-Altava et al., 2017; Esteve-Altava \& Rasskin-Gutman, 2015). For example, by directing

176 mechano-transduction and morphogenetic signals (Khonsari et al., 2013; Katsianou et al., 2016). If

177 that is true, this means that sutures are not only passive subjects of their underlying functional

178 matrices (Moss, 1975), instead they can constrain each other's closure. However, the exact relation

179 between the timing of ossification and suture closure during development is still unclear and may

180 depend on other species-specific anatomical constraints. In humans, for example, the later closure

181 of the metopic suture compared to our extinct relatives and other primates is thought to be an

182 adaptive response to pelvic constraints on the birth canal (Falk et al., 2012).

\section{Mechanical stress and suture closure}

185 Biomechanical studies on vertebrate skulls as disparate as lizards and mammals have shown that 186 cranial sutures relieve strain locally in response to mechanical loads, for example, from chewing

187 (Herring \& Teng, 2000; Moazen et al., 2009; Rafferty \& Herring, 1999). However, using diet

hardness as a proxy, we found no support for an effect of mechanical stress on sutures patency or

closure in mammals. This is either because there is no evolutionary relation between them or

because diet hardness is not a good proxy for the mechanical stress supported by the skull. If diet

hardness is not a good proxy, the most accurate alternative would be to carry out biomechanical

\section{New candidate genes for suture closure in mammals}

196 Following a comparative analysis of protein-coding regions, we identified 28 candidate genes that

197 may have a potential role in determining cranial suture closure in mammalian evolution. Out of this

198 list, three genes-HRNR, KIAA1549, and TTN-are the most likely candidates, because they also

199 show convergent mutations across the whole sample of mammals. These three genes have never 
been associated with neither normal nor pathological craniofacial development. Thus, we can only

201 speculate about their relation to suture closure based on indirect evidence, such as the tissues where

202 they are expressed, their biological function, and their relations to other proteins.

$H R N R$ encodes for a profilaggrin-like protein that functions as an ion binder for calcium and other metals in different tissues (mostly the skin, but also in the brain), organizing the cell envelope and extracellular keratinization. Although $H R N R$ was tentatively reported as a risk factor for craniosynostosis in a study of twins (Rymer, 2015), this result has not been validated (personal communication). HRNR is not known to play a role in cranial development, but other proteins

209 related to keratinization have been reported to participate in developing calvarial bone and sutures

210 (Atsawasuwan et al., 2013). A total of 59 different mutations were found along the entire protein of

$211 H R N R$, none of which targets a functionally active region for calcium binding. However, HRNR-

212 coding region is enriched in methylation sites that undergo modifications during human

213 development from newborn to adult (Salpea et al., 2012), the time when cranial sutures close. We

214 identified 58 convergent substitutions for $H R N R$ in our evolutionary study (the most of all candidate 215 genes), which could be interacting with methylation sites that determine cranial phenotypes during 216 postnatal development.

218 KIAA1549 encodes for a protein component of the cellular membrane that is highly expressed in the 219 brain. Eleven different mutations were found for KIAA1549, none within the transmembrane region. 220 KIAA1549 has never been associated to craniofacial morphology or premature suture closure, but

221 through a fusion with the B-Raf proto-oncogene $(B R A F)$ it has been associated to developing

222 pilocytic astrocytoma, a benign brain tumor (Yamashita et al., 2019). Interestingly, de novo

223 mutations in $B R A F$ has been recently discovered in patients with isolated sagittal synostosis

224 (Armand et al., 2019; Davis et al., 2019). Whether KIAA1549 can affect suture development

225 through its effect on $B R A F$ is not known. 
227 TTN encodes for the largest human protein, a common type of filament present in cardiac and

228 skeletal muscles that is essential for muscle contraction. Thirty-two mutations were found for TTN,

229 none within its active sites. Although TTN has not specifically been associated with craniofacial

230 development or dysmorphologies, we known that head muscles activity is necessary for the correct

231 formation and maintenance of cranial sutures (Byron et al., 2004; Herring \& Teng, 2000; Moss \&

232 Young, 1960). For example, osteoblast in the sutures respond to muscle tension by increasing the

233 formation of bone (Herring, 2008), which is something also observed in craniosynostosis (Al-

234 Rekabi et al., 2017). We can only speculate on whether small changes in TTN proteins modulate

235 head muscles contraction during cranial development, and by doing so, can alter cranial sutures

236 maintenance and closure.

238 The 28 candidate genes for cranial suture closure in evolution are not enriched in biological

239 functions and cellular components often associated with skeletal development (e.g., osteogenesis,

240 growth factor binding, cell proliferation), which are those dysregulated in pathological cases of

241 suture closure (Rojas-Peña et al., 2014). Instead, we found that candidate genes are functionally

242 enriched in proteins for the transport of lipids across the membrane. Lipids play an important role in

243 skeletal metabolism, for example, by limiting permeability of the bone surface and by regulating

244 biomineralization through the transport of essential fat-soluble vitamins D and K (Tintut \& Demer,

245 2014). In the context of cranial sutures, a relationship between vitamin D deficiencies (congenital or

246 nutritional) and craniosynostosis has been known for a long time (Imerslund, 1951; Jaszczuk et al.,

247 2016; Wang et al., 2015). This result suggests that mechanisms of cranial suture closure in

248 evolution could evolve through changes in the regulation of vitamin D transport, rather than acting

249 directly on osteological regulation pathways. Finally, for genes differentially mutated in two out of

250 three of the sutures, we did find enrichments for biological adhesion and components of the 
251 extracellular matrix, which are essential for the maintenance and closure of cranial sutures

252 (Opperman \& Rawlins, 2005; Stamper et al., 2011).

\section{Are evolution and pathological development decoupled for cranial suture closure?}

255 Candidate genes from our evolutionary analysis show a complete lack of overlap with genes linked

256 to pathological suture closure (Adhikari et al., 2016; Justice et al., 2012, 2020; Rojas-Peña et al.,

257 2014). There are many plausible reasons that could explain this mismatch, from methodological

258 limitations to biological causes. On the one hand, the list of genes compared could be incomplete.

259 This is because either (1) our evolutionary analysis fails to identify candidate genes for suture

260 closure or because (2) we only know a limited number of genes which mutation lead to premature

261 suture closure. The first reason would imply that our approach does not work for this phenotype,

262 because it cannot capture mutations affecting the timing of closure (only the mechanism performing

263 the closure), whereas pathological conditions maybe occur due to mutations affecting timing

264 exclusively (e.g., via ectopic gene expression, Poot, 2019). The second reason would mean that our

265 current knowledge of the genetic origins of nonsyndromic craniosynostosis is limited and, therefore,

266 the lists of genes compared fail to capture the complete genetic landscape of this complex disease

267 (Magalhães \& Wang, 2019; Lattanzi et al., 2017). On the other hand, there may be biological

268 reasons that explain this mismatch. As mentioned before, changes in brain growth rates or vitamin

269 D regulation in evolution could be one of such underlying causes, acting differentially for each

270 suture (Barbeito-Andrés et al., 2020).

271

272 Another possibility is that evolutionary mechanisms are decoupled from developmental

273 mechanisms commonly disrupted in disease, so that analogous phenotypic changes (i.e., closing a

274 suture) can proceed through different paths. Decoupling evolutionary mechanisms of phenotypic

275 variation from those genetic pathways whose disruption is most likely to be detrimental for the

276 individual could be a way to maintain evolvability without compromising fitness, bypassing 
277 pleiotropic or epistatic constraints (Payne \& Wagner, 2019). The fact that candidate evolutionary

278 genes for suture closure show no enrichment in any disease set supports this hypothesis. However,

279 it is unclear whether macroevolutionary genetic changes should involve the same loci or mutations

280 uncovered by microevolutionary and clinical studies (Smith et al., 2020). For example, the Runt-

281 related transcription factor $2(R U N X 2)$ is a strongly supported candidate to drive facial

282 morphological and suture closure in human evolution (Adhikari et al., 2016; Magherini et al., 2015)

283 and which mutation causes craniosynostosis (Cuellar et al., 2020; Maeno et al., 2011). However,

284 RUNX2 takes no part in marsupial craniofacial diversity (Newton et al., 2017). This suggests that

285 different mammalian clades can use alternate pathways to control the exact same phenotypic traits.

286

287 Conclusion

288 Our study dissected the phenotypic and genetic causes of cranial suture patency in evolution,

289 highlighting developmental and evolutionary factors for suture closure in mammals. From a

290 phenotypic point of view, we found two main factors: (1) brain growth, which was a known cause

291 of suture patency in normal and pathological development, and (2) sutures self-regulation, which

292 was previously suggested only by theoretical models. From a comparative genomics approach, we

293 identified candidate genes involved in lipid transport, cell adhesion, and the formation of the

294 extracellular matrix. The best supported candidate genes to play a role in cranial suture closure in

295 evolution are $H R N R, K I A A 1549$, and TTN. If validated by additional comparative analyses, and

296 experimentally in model organisms for suture closure (e.g., zebrafish, mice, or rabbit), they could

297 provide new ways to study the genetic basis of suture closure in evolution and disease. To our

298 knowledge, this study is the first attempt to search for the genetic causes of cranial suture closure

299 and associated pathologies at a macroevolutionary scale. Our findings highlight the importance of 300 evolutionary approaches to make new discoveries and test hypothesis on development and disease. 


\section{METHODS}

\section{Sampling}

304 We surveyed an initial sample of 53 species of mammals with multiple sequence alignments of their reference genomes available at UCSC (Kent et al., 2002) and with reliable information on their diet, brain mass, and body mass (Burger et al., 2019). We examined adult skull specimens in vivo and in

307 digital images from museums and online collections with an ID catalog number. A total of 48

308 species had more than two well-preserved specimens available for examination and were included

309 in the present study. Details for specimens ID, suture patency, life traits, phylogeny, and analysis

310 code are available at https://figshare.com/projects/Cranial_Suture_Closure/81209.

\section{Suture patency}

313 For each specimen, we coded the state of the metopic, coronal, and sagittal sutures as either open or 314 closed, depending on whether they were visible (patent) or not (obliterated). Ambiguous cases (e.g., 315 when a suture is half closed) were rare and we excluded them from the study. Suture patency was 316 quantified as the ratio of the number of specimens with the suture open to the total number of

317 specimens examined, ranging from 1 (all open) to 0 (all closed). This continuous measure provided 318 an amenable variable to perform the phylogenetic path analysis. We omitted from our analyses the 319 sagittal suture in the orca and the dolphin, because cetaceans never form this suture in the first place 320 due to the expansion of the occipital bone (Roston \& Roth, 2019).

322 To later search for convergent amino acid substitution (CAAS), suture patency was binarized by

323 thresholding it between 0.75 and 0.25 . A suture with a patency above 0.75 was counted as open and

324 below 0.25 was counted as closed. A binarization of suture patency was necessary because CAAS

325 comparisons require as input two discrete groups of species (Muntané et al., 2018). Because suture

326 patency is a highly conserved trait, most species ranked well above or below these thresholds. Only 
32715 sutures out of 144 observations were left uncategorized, and we omitted them when selecting

328 pairs of species to compare their protein-coding sequences.

\section{Life traits and phylogenetic path analysis}

331 We tested 12 alternative causal models for the closure of the metopic, coronal, and sagittal sutures

332 using a phylogenetic confirmatory path analysis (von Hardenberg \& Gonzalez $\square$ Voyer, 2013). To

333 this end, we downloaded a calibrated phylogeny for all mammals from TimeTree

334 (http://www.timetree.org/) and pruned off the species not sampled. The analysis was carried using

335 the Pagel's lambda model of evolution, which is estimated internally by the function phylo_path

336 (Bijl, 2018) in R (R Core Team, 2019). Figure 4 shows the models evaluated. As potential relations

337 we modeled the mutual causation between sutures due to their development (Koyabu et al., 2014;

338 Rager et al., 2014), the effect of hard diet on sutures due to the stress involving in chewing

339 (Herring, 2008; Rafferty et al., 2019; Sun et al., 2004), and the effect of brain size on sutures due to

340 the influence of the brain on the growth of the bones of the vault and the maintenance of sutures

341 (Richtsmeier, 2018; Richtsmeier et al., 2006; Richtsmeier \& Flaherty, 2013). Finally, we included

342 the effect of diet quality on brain size as an indirect link on sutures (Aiello \& Wheeler, 1995; Allen

$343 \&$ Kay, 2012). To reduce the number of variables in the models, body size was included as a

344 corrector for brain size, instead of as an independent variable.

346 Brain and body mass information was gathered from a recent study on brain size allometry in

347 mammals (Burger et al., 2019). We noticed an error in the body mass for Bos taurus $(46,100 \mathrm{~g})$ and

348 fixed using the correct value $(461,000 \mathrm{~g})$ from the original reference (Isler \& van Schaik, 2012). We

349 favor Burger's dataset because measurements were systematically compiled (e.g., two cross-

350 reference check to assess authenticity of measurements, female-male averages except for dimorphic

351 species), and brain and body mass for each species come from the same study, which minimizes 
352 potential errors. Brain size was calculated as the residual of a phylogenetic generalized least square

353 regression of the log-transformation of brain mass against body mass.

354

355 Diet information was extracted from EltonTraits 1.0 database on species-level foraging attributes

356 (Wilman et al., 2014). Data includes the percentage of the type of food consumed for each species.

357 Diet quality was measured using Sailer and colleagues' equation (Sailer et al., 1985) as, $D Q=$

358 plants $+2 \times($ fruit + seed + nectar $)+3.5 \times($ meat $)$, ranging from 100 to 350 . Because there

359 is not a similar measure for diet hardness based on the relative amount of food consumed, we

360 followed an approach similar to that used for diet quality, measuring diet hardness as, $D H=$

$361($ fruit + meat $)+2 \times($ plants + invertebrates $)+3.5 \times($ seed + scanveing $)$, ranging from 0

362 to 350 (however, only species with a nectar-based diet will rank between 0 and 100). This relative

363 division of food types by hardness (i.e., $1 \mathrm{x}, 2 \mathrm{x}, 3.5 \mathrm{x}$ ) agrees with the division of hard foods used in

364 experimental studies (Marcé-Nogué et al., 2017; Williams et al., 2005). Diet quality and hardness

365 were both normalized between 0 and 1. 


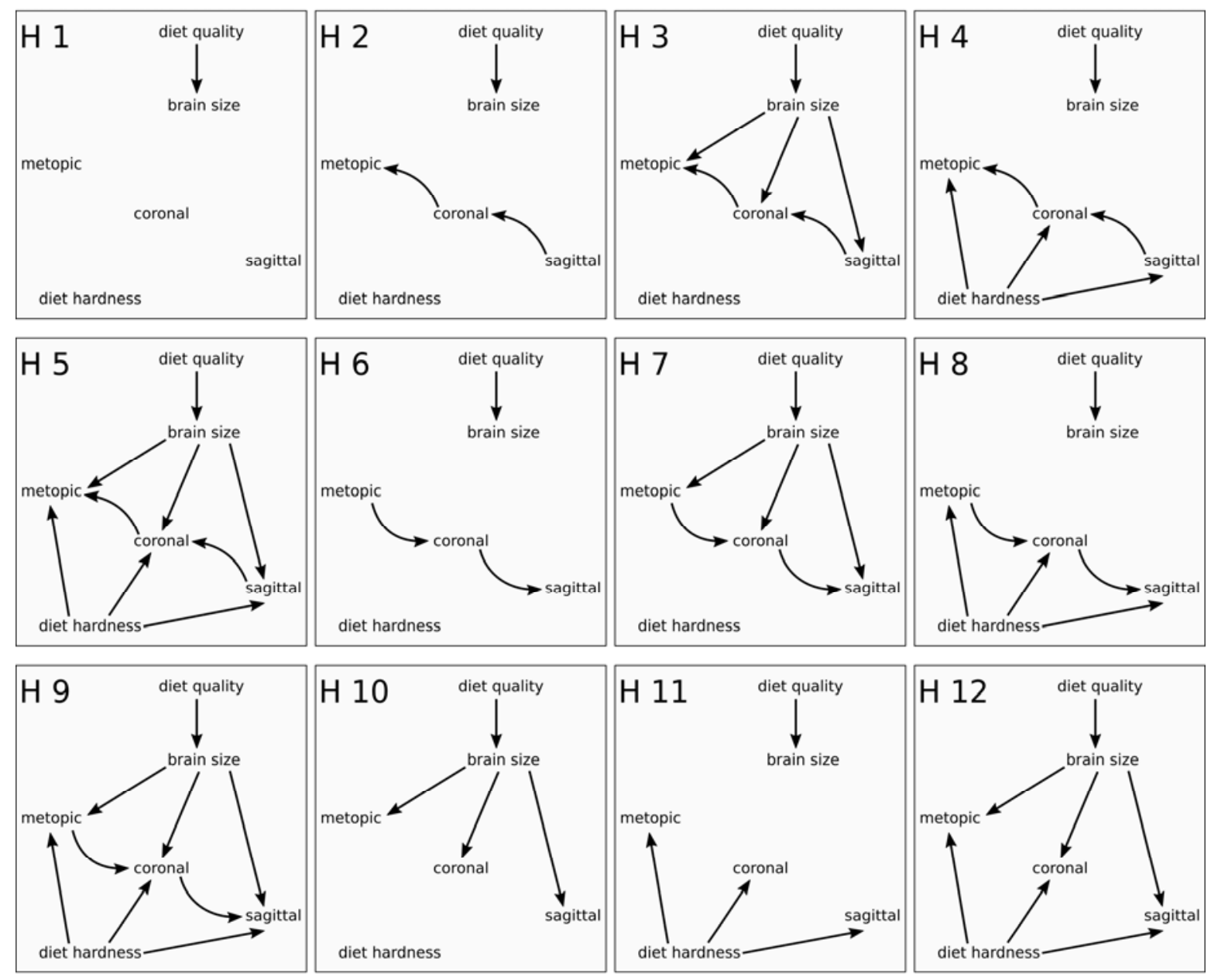

Figure 4. Alternative causal models compared with the phylogenetic path analysis. Model $\mathrm{H} 1$

is the null hypothesis of no causal relation among brain size, diet hardness, and sutures patency.

$\mathrm{H} 2$ to $\mathrm{H} 5$ evaluate the causation of brain and/or diet when suture closure has a causal directionality

following the relative order of closure in mammals (Rager et al., 2014). H6 to H9 evaluate the

causation of brain and/or diet when suture closure follows the anteroposterior timing of ossification

of the skull (Koyabu et al., 2014). $\mathrm{H} 10$ to $\mathrm{H} 12$ evaluate the influence of brain and diet in the

absence of any type of developmental causation between sutures. 


\section{Convergent amino acid substitutions (CAAS)}

369 Multiple sequence alignments (MSA) were downloaded from the University of California Santa

370 Cruz (UCSC) Genome Browser (Kent et al., 2002). We kept the 18533 MSA corresponding to the

371 longest transcript of each gene. We then filtered out those sequences having more than $30 \%$ gaps or

372 ambiguous amino acid definitions in any of the species analyzed. The final background pool of

373 genes included 10922 MSA. On this gene pool, we searched for CAAS that co-occur in three pairs

374 of closely related species with an opposite suture patency (open/closed) for the metopic, coronal,

375 and sagittal sutures (Figure 5), for a total of nine pair-wise comparisons. Using an in-house script

376 from a past study (Muntané et al., 2018), we retrieved all positions in which an amino acid differed

377 between species with the suture open and species with the suture closed. We kept those cases in

378 which an amino acid differed between the two groups and was shared by all the species of at least

379 one group, discarding any case with a gap in that position. The final list of candidate genes includes

380 only those genes that had convergent amino acid substitutions in the compared pairs for the three

381 sutures.

383 We considered three scenarios or types of convergent substitution. Scenario 1 captures the same,

384 single amino acid substitution for all pairs compared between species with the suture open and

385 closed (e.g., open $=\{$ asparagine $\} \rightarrow$ closed $=\{$ histidine $\}$ ). Scenario 2 captures substitutions of a

386 same fixed amino acid in species with the suture open to a variable set of different amino acids in

387 species with the suture closed (e.g., open $=\{$ alanine $\} \rightarrow$ closed $=\{$ proline, glutamate, lysine $\}$ ).

388 Scenario 3 is the reverse case of scenario 2: a variable set of amino acids in species with the suture

389 open changed to a same amino acid in species with the suture closed (e.g., open $=\{$ glutamine,

$390 \quad$ leucine, glycine $\} \rightarrow$ closed $=\{$ lysine $\})$.

391 


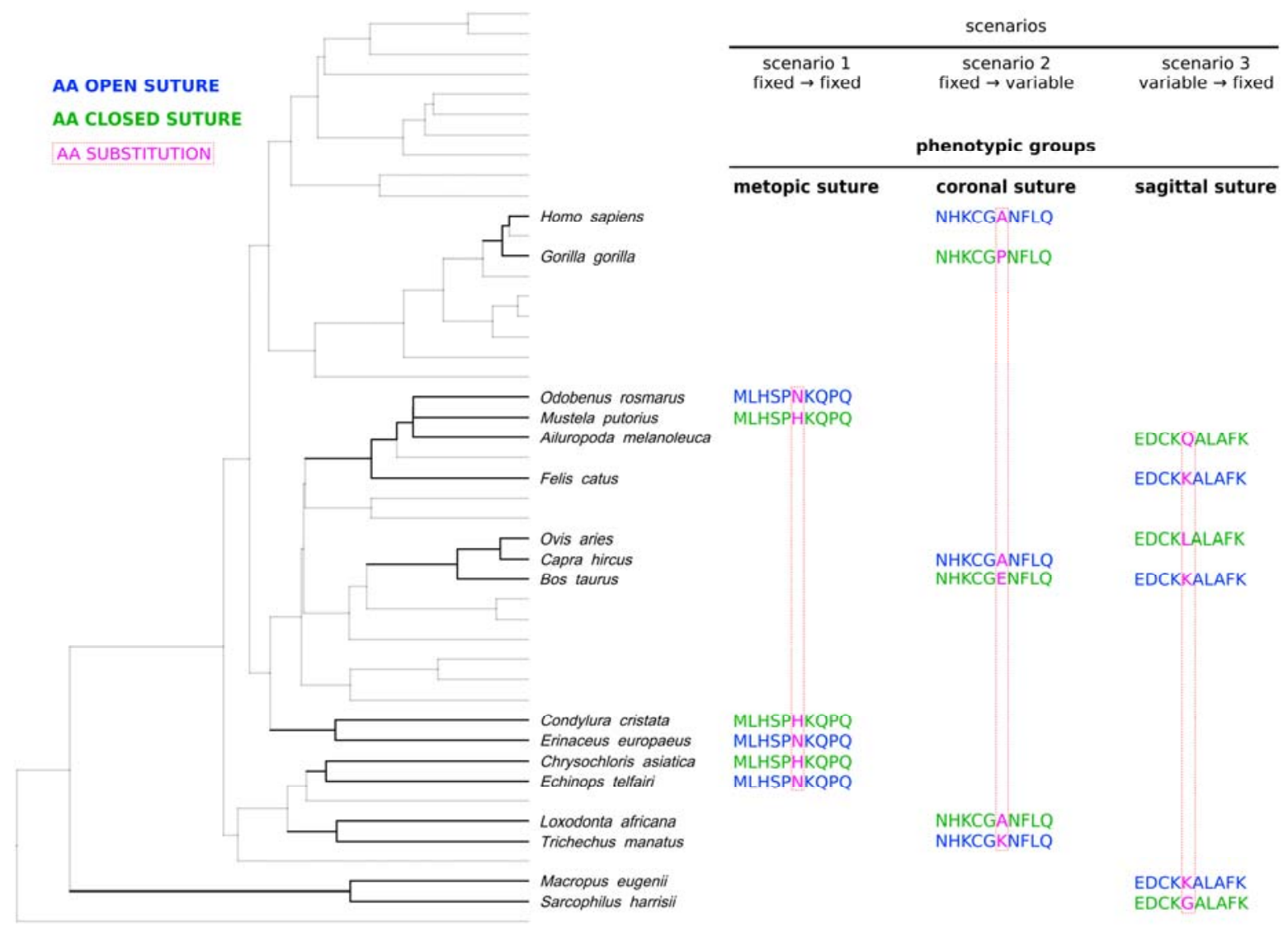

Figure 5. Structure of the convergent amino acid substitution analysis. Pairs of closely related species were selected for comparison based on their suture status as either open (blue) or closed (green), producing three phenotypic groups with three pairs of species each. Three scenarios of substitution were searched for every phenotypic group (only one is shown here for each suture).

\section{Statistical and internal validation of candidate genes}

394 We performed a statistical validation of candidate genes using bootstrapping to assess whether the 395 number of genes carrying CAAS were different than expected at random. For 1000 iterations, we 396 sorted the 17 species analyzed (see Figure 6) into two random groups and scanned the background 397 pool of genes for genes carrying at least one non-gapped CAAS. The bootstrap results span from 3983,274 to 10,681 hits with a median of 8,898 hits, and $5 \%$ and $95 \%$ intervals are $5,759.8$ and 10,082

399 genes hit, respectively. Finally, we tested the significance of the genes overlapping for the three 400 sutures in R using the SuperExactTest package (Wang et al., 2015). 


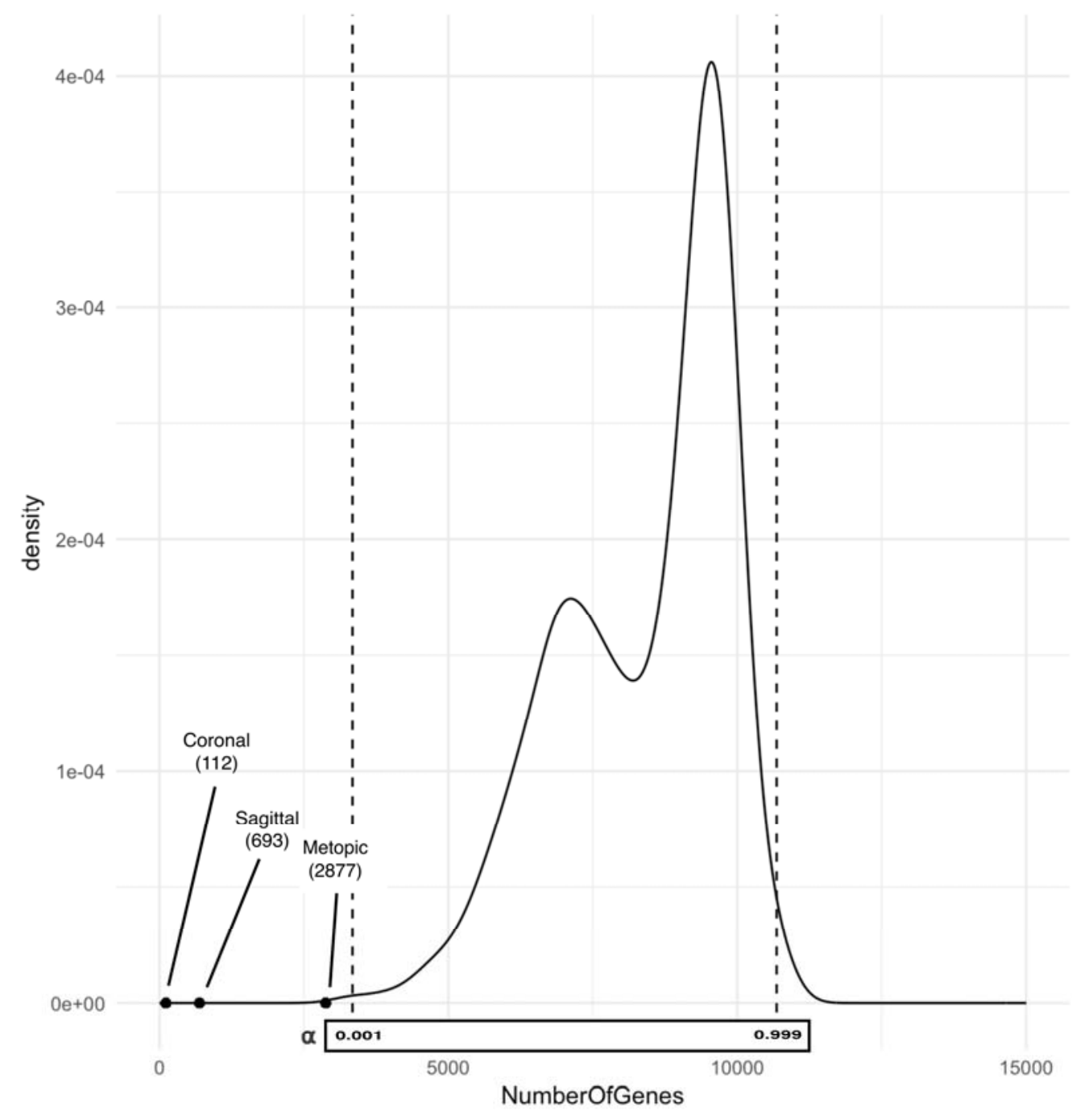

Figure 6. Results of the bootstrap comparisons of CAAS. Red lines show the 0.001 and 0.999 probability limits. Dots mark the total number of genes identified for each suture.

402 To assess biological significance, we performed an internal validation of candidate genes within the

403 whole sample of mammals, following the same procedure described before. We considered a

404 candidate gene as validated when it is also identified carrying open-versus-closed CAAS in the

405 whole sample. Validated genes are discussed in the context of suture biology in more detail. 


\section{Functional and pathological enrichment}

408 We performed set enrichment analyses for the list of candidate gens using GOATOOLS

409 (Klopfenstein et al., 2018) with the background pool of 10,922 protein-coding genes as reference.

410 First, we performed a functional enrichment for biological processes, cellular components, and

411 molecular functions of the Gene Ontology (GO) database (Ashburner et al., 2000;

412 The Gene Ontology Consortium, 2019) using in-house scripts. Enrichments are based on GO

413 definitions present in the go-basic.obo file available on Gene Ontology public database (Accessed

414 February 2020). Then, we performed an enrichment analysis of candidate genes for three sets of

415 genes associated to premature cranial suture closure (craniosynostosis) using Fisher's exact test.

416 The first set comprises 97 genes linked to (mostly) syndromic craniosynostosis conditions in the

417 Human Phenotype Ontology (HP:0001363). The second set comprises 959 genes with differential

418 gene expression profiles in RNA-Seq data for human osteoblast cultures derived from bone biopsy

419 of nonsyndromic craniosynostosis cases (Rojas-Peña et al., 2014). The third set comprises 53 genes

420 from two GWAS studies on nonsyndromic craniosynostosis: one for the sagittal suture (Justice et

421 al., 2012) and one for the metopic suture (Justice et al., 2020). Note that we only included genes

422 that are also present in our background pool of genes.

424 Methodological limitations

425 Suture patency and sample size. The number of specimens examined of each species is uneven, and

426 for some species only a few individuals were available. This is either because the species is rare and

427 was not available in the natural history museums visited or in the online repositories consulted or

428 because the covid-19 outbreak prevented us visiting additional museum collections. However, the

429 conserved nature of suture patency gave us confidence that the suture patency measurements

430 represent the general, highly conserved pattern of each species, and that its categorization as open

431 or closed is valid. A broad sampling would provide stronger support to our conclusions. Moreover, 
432 it would make possible to include intraspecific variation within the analysis, which was not possible

433 now because some species (perhaps due to the small sample size) showed little variation.

434

435 Quality of referenced genomes, alignments, and number of gaps. The quality of the mammalian

436 reference genomes available for comparison is also uneven; specially compared to human and some

437 model organisms. The consequence is that some alignments of protein-coding genes have a high

438 number of gaps (i.e., not comparable positions because of unknown amino acid, deletion/insertion).

439 These gapped positions complicate comparing simultaneously many species. In this study, we

440 decided to take the most conservative approach: we excluded genes with more than $30 \%$ of

441 positions with a gap from the background pool and also positions with gaps for each pairwise

442 CAAS. The side effect of this strategy is that some genes are inevitably excluded because they

443 show many gaps, among them genes linked to craniofacial development, such as ALX4, ERF,

444 SMAD6. In addition, protein lengths may exert some bias in the genes excluded as well as the

445 number of CAAS. Nevertheless, we adopted this conservative approach because the laxer

446 alternative added an additional layer of ambiguity in the results. We hope that soon more and better

447 referenced genomes will be available that allow expanding our comparative study. 


\section{ACKNOWLDEGEMENTS}

This work will not have been possible without the help from many colleagues that shared their museum skull photographs and CT scans, which mitigated the impossibility to visit museum collections due to COVID-19 lockdowns worldwide. We thank Borja Figueirido, Georgina Hutton, Jordi Marcé-Nogué, Laura O. Wilson, Mathew J. Stewart, Patrick Arnold, and Soledad De Esteban Trivigno. Also, to Christopher Smith for his photographs from the American Museum of Natural History, New York. We also thank curators Javier Quesada (Museum of Zoology of Barcelona), Ángel Luís Garvía Rodriguez and Luís Castelo Vicente (National Museum of Natural Sciences) for their help in accessing specimens. Finally, we are thankful to Tomàs Marquès-Bonet and his group, specially David Juan, for their insights and feedback.

\section{FUNDING}

BE-A has received financial support for this project by the Postdoctoral Junior Leader Fellowship Programme from "la Caixa" Banking Foundation (LCF/BQ/LI18/11630002). BE-A and AN are supported by AEI-PGC2018-101927-BI00 (FEDER/UE). We also thank the Unidad de Excelencia María de Maeztu funded by the AEI (CEX2018-000792-M).

\section{COMPETING INTERESTS}

Authors declare no competing interests.

\section{DATA AND CODE AVAILABILITY}

Data and code used in this manuscript is available at https://figshare.com/projects/Cranial_Suture_Closure/81209

\section{AUTHOR CONTRIBUTIONS}

BE-A designed the study, collected the data, and wrote the manuscript. 
BE-A and FB analyzed the data.

FB, XF, GM, and AN conceived and designed the in-house scripts for CAAS.

All authors interpreted the results and wrote the manuscript.

\section{REFERENCES}

Adhikari, K., Fuentes-Guajardo, M., Quinto-Sánchez, M., Mendoza-Revilla, J., Camilo ChacónDuque, J., Acuña-Alonzo, V., Jaramillo, C., Arias, W., Lozano, R. B., Pérez, G. M., Gómez-Valdés, J., Villamil-Ramírez, H., Hunemeier, T., Ramallo, V., Silva de Cerqueira, C. C., Hurtado, M., Villegas, V., Granja, V., Gallo, C., ... Ruiz-Linares, A. (2016). A genome-wide association scan implicates DCHS2, RUNX2, GLI3, PAX1 and EDAR in human facial variation. Nature Communications, 7, 11616. https://doi.org/10.1038/ncomms11616

Aiello, L. C., \& Wheeler, P. (1995). The expensive-tissue hypothesis: The brain and the digestive system in human and primate evolution. Current Anthropology, 36(2), 199-221. https://doi.org/10.1086/204350.

Alföldi, J., \& Lindblad-Toh, K. (2013). Comparative genomics as a tool to understand evolution and disease. Genome Research, 23(7), 1063-1068. https://doi.org/10.1101/gr.157503.113

Allen, K. L., \& Kay, R. F. (2012). Dietary quality and encephalization in platyrrhine primates. Proceedings of the Royal Society B: Biological Sciences, 279(1729), 715-721. https://doi.org/10.1098/rspb.2011.1311

Al-Rekabi, Z., Cunningham, M. L., \& Sniadecki, N. J. (2017). Cell mechanics of craniosynostosis. ACS Biomaterials Science \& Engineering, 3(11), 2733-2743. https://doi.org/10.1021/acsbiomaterials.6b00557

Armand, T., Schaefer, E., Di Rocco, F., Edery, P., Collet, C., \& Rossi, M. (2019). Genetic bases of craniosynostoses: An update. Neuro-Chirurgie, 65(5), 196-201. https://doi.org/10.1016/j.neuchi.2019.10.003 
Ashburner, M., Ball, C. A., Blake, J. A., Botstein, D., Butler, H., Cherry, J. M., \& Davis, A. P. (2000). Gene Ontology: Tool for the unification of biology. Nature Genetics, 25(1), 25-29. https://doi.org/10.1038/75556.

Atsawasuwan, P., Lu, X., Ito, Y., Zhang, Y., Evans, C. A., \& Luan, X. (2013). Ameloblastin inhibits cranial suture closure by modulating Msx2 expression and proliferation. PLOS ONE, 8(4), e52800. https://doi.org/10.1371/journal.pone.0052800

Barbeito-Andrés, J., Bonfili, N., Nogué, J. M., Bernal, V., \& Gonzalez, P. N. (2020). Modeling the effect of brain growth on cranial bones using finite-element analysis and geometric morphometrics. Surgical and Radiologic Anatomy. https://doi.org/10.1007/s00276-02002466-y

Bärmann, E. V., \& Sánchez-Villagra, M. R. (2012). A phylogenetic study of late growth events in a mammalian evolutionary radiation: The cranial sutures of terrestrial artiodactyl mammals. Journal of Mammalian Evolution, 19(1), 43-56. https://doi.org/10.1007/s10914-011-9176-8

Bijl, W. van der. (2018). Phylopath: Easy phylogenetic path analysis in R. PeerJ, 6, e4718. https://doi.org/10.7717/peerj.4718

Bright, J. A. (2012). The importance of craniofacial sutures in biomechanical finite element models of the domestic pig. PLOS ONE, 7(2), e31769. https://doi.org/10.1371/journal.pone.0031769

Burger, J. R., George, M. A., Leadbetter, C., \& Shaikh, F. (2019). The allometry of brain size in mammals. Journal of Mammalogy, 100(2), 276-283. https://doi.org/10.1093/jmammal/gyz043

Byron, C. D., Borke, J., Yu, J., Pashley, D., Wingard, C. J., \& Hamrick, M. (2004). Effects of increased muscle mass on mouse sagittal suture morphology and mechanics. The Anatomical Record Part A: Discoveries in Molecular, Cellular, and Evolutionary Biology, 279A(1), 676-684. https://doi.org/10.1002/ar.a.20055 
Cohen, M., \& MacLean, R. (2000). Craniosynostosis: Diagnosis, evaluation, and management. Oxford University Press.

Cornille, M., Dambroise, E., Komla-Ebri, D., Kaci, N., Biosse-Duplan, M., Rocco, F. D., \& LegeaiMallet, L. (2019). Animal models of craniosynostosis. Neurochirurgie, 65(5), 202-209. https://doi.org/10.1016/j.neuchi.2019.09.010

Cray, J., Cooper, G. M., Mooney, M. P., \& Siegel, M. I. (2014). Ectocranial suture fusion in primates: Pattern and phylogeny. Journal of Morphology, 275(3), 342-347. https://doi.org/10.1002/jmor.20218

Cuellar, A., Bala, K., Di Pietro, L., Barba, M., Yagnik, G., Liu, J. L., Stevens, C., Hur, D. J., Ingersoll, R. G., Justice, C. M., Drissi, H., Kim, J., Lattanzi, W., \& Boyadjiev, S. A. (2020). Gain-of-function variants and overexpression of RUNX2 in patients with nonsyndromic midline craniosynostosis. Bone, 115395. https://doi.org/10.1016/j.bone.2020.115395

Davis, A. A., Zuccoli, G., Haredy, M. M., Losee, J., Pollack, I. F., Madan-Khetarpal, S., Goldstein, J. A., \& Nischal, K. K. (2019). RASopathy in patients with isolated sagittal synostosis. Global Pediatric Health. https://doi.org/10.1177/2333794X19846774

de Magalhães, J. P., \& Wang, J. (2019). The fog of genetics: What is known, unknown and unknowable in the genetics of complex traits and diseases. EMBO Reports, 20(11), e48054. https://doi.org/10.15252/embr.201948054

Dempsey, R. F., Monson, L. A., Maricevich, R. S., Truong, T. A., Olarunnipa, S., Lam, S. K., Dauser, R. C., Hollier, L. H., \& Buchanan, E. P. (2019). Nonsyndromic craniosynostosis. Clinics in Plastic Surgery, 46(2), 123-139. https://doi.org/10.1016/j.cps.2018.11.001

Esteve-Altava, B., \& Rasskin-Gutman, D. (2014). Beyond the functional matrix hypothesis: A network null model of human skull growth for the formation of bone articulations. Journal of Anatomy, 225(3), 306-316. https://doi.org/10.1111/joa.12212

Esteve-Altava, B., \& Rasskin-Gutman, D. (2015). Evo-Devo insights from pathological networks: Exploring craniosynostosis as a developmental mechanism for modularity and complexity 
in the human skull. Journal of Anthropological Sciences, 93, 103-117.

https://doi.org/10.4436/JASS.93001

Esteve-Altava, B., Vallès-Català, T., Guimerà, R., Sales-Pardo, M., \& Rasskin-Gutman, D. (2017).

Bone fusion in normal and pathological development is constrained by the network

architecture of the human skull. Scientific Reports, 7(1), 3376.

https://doi.org/10.1038/s41598-017-03196-9

Falk, D., Zollikofer, C. P. E., Morimoto, N., \& Ponce de Leon, M. S. (2012). Metopic suture of Taung (Australopithecus africanus) and its implications for hominin brain evolution.

Proceedings of the National Academy of Sciences, 109(22), 8467-8470.

https://doi.org/10.1073/pnas.1119752109

Foote, A. D., Liu, Y., Thomas, G. W. C., Vinař, T., Alföldi, J., Deng, J., Dugan, S., van Elk, C. E., Hunter, M. E., Joshi, V., Khan, Z., Kovar, C., Lee, S. L., Lindblad-Toh, K., Mancia, A., Nielsen, R., Qin, X., Qu, J., Raney, B. J., ... Gibbs, R. A. (2015). Convergent evolution of the genomes of marine mammals. Nature Genetics, 47(3), 272-275. https://doi.org/10.1038/ng.3198

Garza, R. M., \& Khosla, R. K. (2012). Nonsyndromic craniosynostosis. Seminars in Plastic Surgery, 26(2), 53-63. https://doi.org/10.1055/s-0032-1320063

Green, R. E., Krause, J., Briggs, A. W., Maricic, T., Stenzel, U., Kircher, M., Patterson, N., Li, H., Zhai, W., Fritz, M. H.-Y., Hansen, N. F., Durand, E. Y., Malaspinas, A.-S., Jensen, J. D., Marques-Bonet, T., Alkan, C., Prüfer, K., Meyer, M., Burbano, H. A., .. Pääbo, S. (2010). A draft sequence of the Neandertal genome. Science (New York, N.Y.), 328(5979), 710 722. https://doi.org/10.1126/science.1188021

Grova, M., Lo, D. D., Montoro, D., Hyun, J. S., Chung, M. T., Wan, D. C., \& Longaker, M. T. (2012). Animal models of cranial suture biology. The Journal of Craniofacial Surgery, 23(7 0 1), 1954-1958. https://doi.org/10.1097/SCS.0b013e318258ba53 
Herring, S. W. (2008). Mechanical influences on suture development and patency. In D. P. Rice

(Ed.), Craniofacial Sutures. Development, Disease and Treatment (Vol. 12, pp. 41-56). S.

KARGER AG. https://doi.org/10.1159/000115031

Herring, \& Teng, S. (2000). Strain in the braincase and its sutures during function. American

Journal of Physical Anthropology, 112(4), 575-593. https://doi.org/10.1002/1096-

8644(200008)112:4<575::AID-AJPA10>3.0.CO;2-0

Imerslund, O. (1951). Craniostenosis and vitamin D resistant rickets. Acta Paediatrica, 40(5), 449456. https://doi.org/10.1111/j.1651-2227.1951.tb16509.x

Isler, K., \& van Schaik, C. P. (2012). Allomaternal care, life history and brain size evolution in mammals. Journal of Human Evolution, 63(1), 52-63.

https://doi.org/10.1016/j.jhevol.2012.03.009

Jaszczuk, P., Rogers, G. F., Guzman, R., \& Proctor, M. R. (2016). X-linked hypophosphatemic rickets and sagittal craniosynostosis: Three patients requiring operative cranial expansion: case series and literature review. Child's Nervous System, 32(5), 887-891. https://doi.org/10.1007/s00381-015-2934-9

Justice, C. M., Cuellar, A., Bala, K., Sabourin, J. A., Cunningham, M. L., Crawford, K., Phipps, J. M., Zhou, Y., Cilliers, D., Byren, J. C., Johnson, D., Wall, S. A., Morton, J. E. V., Noons, P., Sweeney, E., Weber, A., Rees, K. E. M., Wilson, L. C., Simeonov, E., ... National Birth Defects Prevention Study. (2020). A genome-wide association study implicates the BMP7 locus as a risk factor for nonsyndromic metopic craniosynostosis. Human Genetics. https://doi.org/10.1007/s00439-020-02157-z

Justice, C. M., Yagnik, G., Kim, Y., Peter, I., Jabs, E. W., Erazo, M., Ye, X., Ainehsazan, E., Shi, L., Cunningham, M. L., Kimonis, V., Roscioli, T., Wall, S. A., Wilkie, A. O. M., Stoler, J., Richtsmeier, J. T., Heuzé, Y., Sanchez-Lara, P. A., Buckley, M. F., ... Boyadjiev, S. A. (2012). A genome-wide association study identifies susceptibility loci for nonsyndromic 
sagittal craniosynostosis near BMP2 and within BBS9. Nature Genetics, 44(12), 13601364. https://doi.org/10.1038/ng.2463

Katsianou, M. A., Adamopoulos, C., Vastardis, H., \& Basdra, E. K. (2016). Signaling mechanisms implicated in cranial sutures pathophysiology: Craniosynostosis. BBA Clinical, 6, 165-176. https://doi.org/10.1016/j.bbacli.2016.04.006

Kent, W. J., Sugnet, C. W., Furey, T. S., Roskin, K. M., Pringle, T. H., Zahler, A. M., \& Haussler, and D. (2002). The human genome browser at UCSC. Genome Research, 12(6), 996-1006. https://doi.org/10.1101/gr.229102

Khonsari, R. H., Olivier J., Vigneaux P., Sanchez S., Tafforeau P., Ahlberg P. E., Di Rocco F., Bresch D., Corre P., Ohazama A., Sharpe P. T., \& Calvez V. (2013). A mathematical model for mechanotransduction at the early steps of suture formation. Proceedings of the Royal Society B, 280(1759), 20122670. https://doi.org/10.1098/rspb.2012.2670

Klopfenstein, D. V., Zhang, L., Pedersen, B. S., Ramírez, F., Warwick Vesztrocy, A., Naldi, A., Mungall, C. J., Yunes, J. M., Botvinnik, O., Weigel, M., Dampier, W., Dessimoz, C., Flick, P., \& Tang, H. (2018). GOATOOLS: A Python library for Gene Ontology analyses. Scientific Reports, 8(1), 10872. https://doi.org/10.1038/s41598-018-28948-z

Koyabu, D., Endo, H., Mitgutsch, C., Suwa, G., Catania, K. C., Zollikofer, C. P., Oda, S., Koyasu, K., Ando, M., \& Sánchez-Villagra, M. R. (2011). Heterochrony and developmental modularity of cranial osteogenesis in lipotyphlan mammals. EvoDevo, 2(1), 21. https://doi.org/10.1186/2041-9139-2-21

Koyabu, D., Werneburg, I., Morimoto, N., Zollikofer, C. P. E., Forasiepi, A. M., Endo, H., Kimura, J., Ohdachi, S. D., Truong Son, N., \& Sánchez-Villagra, M. R. (2014). Mammalian skull heterochrony reveals modular evolution and a link between cranial development and brain size. Nature Communications, 5(1). https://doi.org/10.1038/ncomms4625 
Lattanzi, W., Barba, M., Di Pietro, L., \& Boyadjiev, S. A. (2017). Genetic advances in craniosynostosis. American Journal of Medical Genetics, 173(5), 1406-1429. https://doi.org/10.1002/ajmg.a.38159

Lieberman, D. E. (2010). The Evolution of the Human Head. Belknap Press Harvard University Press.

Lieberman, D. E. (2011). Epigenetic integration, complexity, and evolvability of the head. In B. Hallgrímsson \& B. K. Hall (Eds.), Epigenetics. Linking Genotype and Phenotype in Development and Evolution (pp. 271-289). University of California Press.

Maeno, T., Moriishi, T., Yoshida, C. A., Komori, H., Kanatani, N., Izumi, S., Takaoka, K., \& Komori, T. (2011). Early onset of Runx2 expression caused craniosynostosis, ectopic bone formation, and limb defects. Bone, 49(4), 673-682.

https://doi.org/10.1016/j.bone.2011.07.023

Magherini, S., Fiore, M. G., Chiarelli, B., Serrao, A., Paternostro, F., Morucci, G., Branca, J. J. V., Ruggiero, M., \& Pacini, S. (2015). Metopic suture and RUNX2, a key transcription factor in osseous morphogenesis with possible important implications for human brain evolution. Italian Journal of Anatomy and Embryology, 120(1), 5-20.

Marcé-Nogué, J., Püschel, T. A., \& Kaiser, T. M. (2017). A biomechanical approach to understand the ecomorphological relationship between primate mandibles and diet. Scientific Reports, 7(1), 1-12. https://doi.org/10.1038/s41598-017-08161-0

Moazen, M., Curtis, N., O’Higgins, P., Jones, M. E. H., Evans, S. E., \& Fagan, M. J. (2009). Assessment of the role of sutures in a lizard skull: A computer modelling study. Proceedings of the Royal Society B: Biological Sciences, 276(1654), 39-46. https://doi.org/10.1098/rspb.2008.0863

Morriss-Kay, G. M., \& Wilkie, A. O. M. (2005). Growth of the normal skull vault and its alteration in craniosynostosis: Insights from human genetics and experimental studies. Journal of Anatomy, 207(5), 637-653. https://doi.org/10.1111/j.1469-7580.2005.00475.x 
Moss, M. L. (1975). Functional anatomy of cranial synostosis. Child's Brain, 1(1), 22-33.

Moss, M. L., \& Young, R. W. (1960). A functional approach to craniology. American Journal of Physical Anthropology, 18(4), 281-292.

Muntané, G., Farré, X., Rodríguez, J. A., Pegueroles, C., Hughes, D. A., de Magalhães, J. P., Gabaldón, T., \& Navarro, A. (2018). Biological processes modulating longevity across primates: A phylogenetic genome-phenome analysis. Molecular Biology and Evolution, 35(8), 1990-2004. https://doi.org/10.1093/molbev/msy105

Newton, A. H., Feigin, C. Y., \& Pask, A. J. (2017). RUNX2 repeat variation does not drive craniofacial diversity in marsupials. BMC Evolutionary Biology, 17(1). https://doi.org/10.1186/s12862-017-0955-6

Oh, J., Kim, Y. K., Yasuda, M., Koyabu, D., \& Kimura, J. (2017). Cranial suture closure pattern in water deer and implications of suture evolution in cervids. Mammalian Biology, 86, 17-20. https://doi.org/10.1016/j.mambio.2017.03.004

Opperman, L. A. (2000). Cranial sutures as intramembranous bone growth sites. Developmental Dynamics, 219, 472-485.

Opperman, L. A., \& Rawlins, J. T. (2005). The extracellular matrix environment in suture morphogenesis and growth. Cells, Tissues, Organs, 181(3-4), 127-135. https://doi.org/10.1159/000091374

Payne, J. L., \& Wagner, A. (2019). The causes of evolvability and their evolution. Nature Reviews Genetics, 20(1), 24-38. https://doi.org/10.1038/s41576-018-0069-z

Poot, M. (2019). Structural genome variations related to craniosynostosis. Molecular Syndromology, 10(1-2), 24-39. https://doi.org/10.1159/000490480

R Core Team. (2019). R: A language and environment for statistical computing (Version 3.6.2) [Computer software]. R Foundation for Statistical Computing. https://www.R-project.org/ 
Rafferty, K. L., Baldwin, M. C., Soh, S. H., \& Herring, S. W. (2019). Mechanobiology of bone and suture-Results from a pig model. Orthodontics \& Craniofacial Research, 22 Suppl 1, 8289. https://doi.org/10.1111/ocr.12276

Rafferty, K. L., \& Herring, S. W. (1999). Craniofacial sutures: Morphology, growth, and in vivo masticatory strains. Journal of Morphology, 242(2), 167-179. https://doi.org/10.1002/(SICI)1097-4687(199911)242:2<167::AID-JMOR8>3.0.CO;2-1

Rager, L., Hautier, L., Forasiepi, A., Goswami, A., \& Sánchez-Villagra, M. R. (2014). Timing of cranial suture closure in placental mammals: Phylogenetic patterns, intraspecific variation, and comparison with marsupials. Journal of Morphology, 275(2), 125-140.

https://doi.org/10.1002/jmor.20203

Rasskin-Gutman, D., \& Esteve-Altava, B. (2018). Concept of burden in evo-devo. In L. Nuno de la Rosa \& G. Müller (Eds.), Evolutionary Developmental Biology: A Reference Guide (pp. 111). Springer International Publishing.

Richtsmeier, J. T. (2018). A century of development. American Journal of Physical Anthropology, 165(4), 726-740. https://doi.org/10.1002/ajpa.23379

Richtsmeier, J. T., Aldridge, K., DeLeon, V. B., Panchal, J., Kane, A. A., Marsh, J. L., Yan, P., \& Cole, T. M. (2006). Phenotypic integration of neurocranium and brain. Journal of Experimental Zoology Part B: Molecular and Developmental Evolution, 306B(4), 360-378. https://doi.org/10.1002/jez.b.21092

Richtsmeier, J. T., \& Flaherty, K. (2013). Hand in glove: Brain and skull in development and dysmorphogenesis. Acta Neuropathologica, 125(4), 469-489. https://doi.org/10.1007/s00401-013-1104-y

Rojas-Peña, M. L., Olivares-Navarrete, R., Hyzy, S., Arafat, D., Schwartz, Z., Boyan, B. D., Williams, J., \& Gibson, G. (2014). Characterization of distinct classes of differential gene expression in osteoblast cultures from non-syndromic craniosynostosis bone. Journal of Genomics, 2, 121-130. https://doi.org/10.7150/jgen.8833 
Roosenboom, J., Lee, M. K., Hecht, J. T., Heike, C. L., Wehby, G. L., Christensen, K., Feingold, E., Marazita, M. L., Maga, A. M., Shaffer, J. R., \& Weinberg, S. M. (2018). Mapping genetic variants for cranial vault shape in humans. PLOS ONE, 13(4), e0196148. https://doi.org/10.1371/journal.pone.0196148

Roston, R. A., \& Roth, V. L. (2019). Cetacean skull telescoping brings evolution of cranial sutures into focus. The Anatomical Record, 302(7), 1055-1073. https://doi.org/10.1002/ar.24079

Rymer, K. (2015). Identification of Candidate Genes for Craniosynostosis [Virginia Commonwealth University]. https://scholarscompass.vcu.edu/etd/3782

Sailer, L. D., Gaulin, S. J. C., Boster, J. S., \& Kurland, J. A. (1985). Measuring the relationship between dietary quality and body size in primates. Primates, 26(1), 14-27. https://doi.org/10.1007/BF02389044

Salpea, P., Russanova, V. R., Hirai, T. H., Sourlingas, T. G., Sekeri-Pataryas, K. E., Romero, R., Epstein, J., \& Howard, B. H. (2012). Postnatal development- and age-related changes in DNA-methylation patterns in the human genome. Nucleic Acids Research, 40(14), 64776494. https://doi.org/10.1093/nar/gks312

Sewda, A., White, S. R., Erazo, M., Hao, K., García-Fructuoso, G., Fernández-Rodriguez, I., Heuzé, Y., Richtsmeier, J. T., Romitti, P. A., Reva, B., Jabs, E. W., \& Peter, I. (2019). Nonsyndromic craniosynostosis: Novel coding variants. Pediatric Research, 85(4), 463468. https://doi.org/10.1038/s41390-019-0274-2

Smith, S. D., Pennell, M. W., Dunn, C. W., \& Edwards, S. V. (2020). Phylogenetics is the new genetics (for most of biodiversity). Trends in Ecology \& Evolution, 35(5), 415-425. https://doi.org/10.1016/j.tree.2020.01.005

Spector, J. A., Greenwald, J. A., Warren, S. M., Bouletreau, P. J., Crisera, F. E., Mehrara, B. J., \& Longaker, M. T. (2002). Co-culture of osteoblasts with immature dural cells causes an increased rate and degree of osteoblast differentiation. Plastic and Reconstructive Surgery, 109(2), 631-642. https://doi.org/10.1097/00006534-200202000-00033 
Stamper, B. D., Park, S. S., Beyer, R. P., Bammler, T. K., Farin, F. M., Mecham, B., \&

Cunningham, M. L. (2011). Differential expression of extracellular matrix-mediated pathways in single-suture craniosynostosis. PLOS ONE, 6(10). https://doi.org/10.1371/journal.pone.0026557

Sun, Z., Lee, E., \& Herring, S. W. (2004). Cranial sutures and bones: Growth and fusion in relation to masticatory strain. The Anatomical Record, 276(2), 150-161. https://doi.org/10.1002/ar.a.20002

The Gene Ontology Consortium. (2019). The Gene Ontology Resource: 20 years and still GOing strong. Nucleic Acids Research, 47(D1), D330-D338. https://doi.org/10.1093/nar/gky1055

Tintut, Y., \& Demer, L. L. (2014). Effects of bioactive lipids and lipoproteins on bone. Trends in Endocrinology and Metabolism, 25(2), 53-59. https://doi.org/10.1016/j.tem.2013.10.001

Twigg, S. R. F., Forecki, J., Goos, J. A. C., Richardson, I. C. A., Hoogeboom, A. J. M., van den Ouweland, A. M. W., Swagemakers, S. M. A., Lequin, M. H., Van Antwerp, D., McGowan, S. J., Westbury, I., Miller, K. A., Wall, S. A., WGS500 Consortium, van der Spek, P. J., Mathijssen, I. M. J., Pauws, E., Merzdorf, C. S., \& Wilkie, A. O. M. (2015). Gain-of-function mutations in ZIC1 are associated with coronal craniosynostosis and learning disability. American Journal of Human Genetics, 97(3), 378-388. https://doi.org/10.1016/j.ajhg.2015.07.007

Twigg, S. R. F., \& Wilkie, A. O. M. (2015). A genetic-pathophysiological framework for craniosynostosis. American Journal of Human Genetics, 97(3), 359-377. https://doi.org/10.1016/j.ajhg.2015.07.006

von Hardenberg, A., \& Gonzalez $\square$ Voyer, A. (2013). Disentangling evolutionary cause-effect relationships with phylogenetic confirmatory path analysis. Evolution, 67(2), 378-387. https://doi.org/10.1111/j.1558-5646.2012.01790.x

Wang, M., Zhao, Y., \& Zhang, B. (2015). Efficient test and visualization of multi-set intersections. Scientific Reports, 5(1), 16923. https://doi.org/10.1038/srep16923 
Wang, P. I., Marcus, J. R., Fuchs, H. E., \& Mukundan, S. (2015). Craniosynostosis secondary to rickets: Manifestations on computed tomography. Radiology Case Reports, 2(3). https://doi.org/10.2484/rcr.v2i3.43

Wilkie, A. O. M., Johnson, D., \& Wall, S. A. (2017). Clinical genetics of craniosynostosis. Current Opinion in Pediatrics, 29(6), 622-628. https://doi.org/10.1097/MOP.0000000000000542

Williams, S. H., Wright, B. W., Truong, V. den, Daubert, C. R., \& Vinyard, C. J. (2005). Mechanical properties of foods used in experimental studies of primate masticatory function. American Journal of Primatology, 67(3), 329-346. https://doi.org/10.1002/ajp.20189

Wilman, H., Belmaker, J., Simpson, J., Rosa, C. de la, Rivadeneira, M. M., \& Jetz, W. (2014). EltonTraits 1.0: Species-level foraging attributes of the world's birds and mammals. Ecology, 95(7), 2027-2027. https://doi.org/10.1890/13-1917.1

Wilson, L. A. B., \& Sánchez $\square$ Villagra, M. R. (2009). Heterochrony and patterns of cranial suture closure in hystricognath rodents. Journal of Anatomy, 214(3), 339-354. https://doi.org/10.1111/j.1469-7580.2008.01031.x

Wu, D.-D., Jin, W., Hao, X.-D., Tang, N. L. S., \& Zhang, Y.-P. (2010). Evidence for positive selection on the osteogenin (BMP3) gene in human populations. PLOS ONE, 5(6), e10959. https://doi.org/10.1371/journal.pone.0010959

Wu, D.-D., Li, G.-M., Jin, W., Li, Y., \& Zhang, Y.-P. (2012). Positive selection on the osteoarthritis-risk and decreased-height associated variants at the GDF5 Gene in East Asians. PLOS ONE, 7(8), e42553. https://doi.org/10.1371/journal.pone.0042553

Yamashita, S., Takeshima, H., Matsumoto, F., Yamasaki, K., Fukushima, T., Sakoda, H., Nakazato, M., Saito, K., Mizuguchi, A., Watanabe, T., Ohta, H., \& Yokogami, K. (2019). Detection of the KIAA1549-BRAF fusion gene in cells forming microvascular proliferations in pilocytic astrocytoma. PLOS ONE, 14(7), e0220146. https://doi.org/10.1371/journal.pone.0220146 
bioRxiv preprint doi: https://doi.org/10.1101/2020.06.15.148130; this version posted June 15, 2020. The copyright holder for this preprint (which was not certified by peer review) is the author/funder, who has granted bioRxiv a license to display the preprint in perpetuity. It is made available under aCC-BY-NC-ND 4.0 International license.

Zhou, X., Seim, I., \& Gladyshev, V. N. (2015). Convergent evolution of marine mammals is associated with distinct substitutions in common genes. Scientific Reports, 5(1), 16550. https://doi.org/10.1038/srep16550 


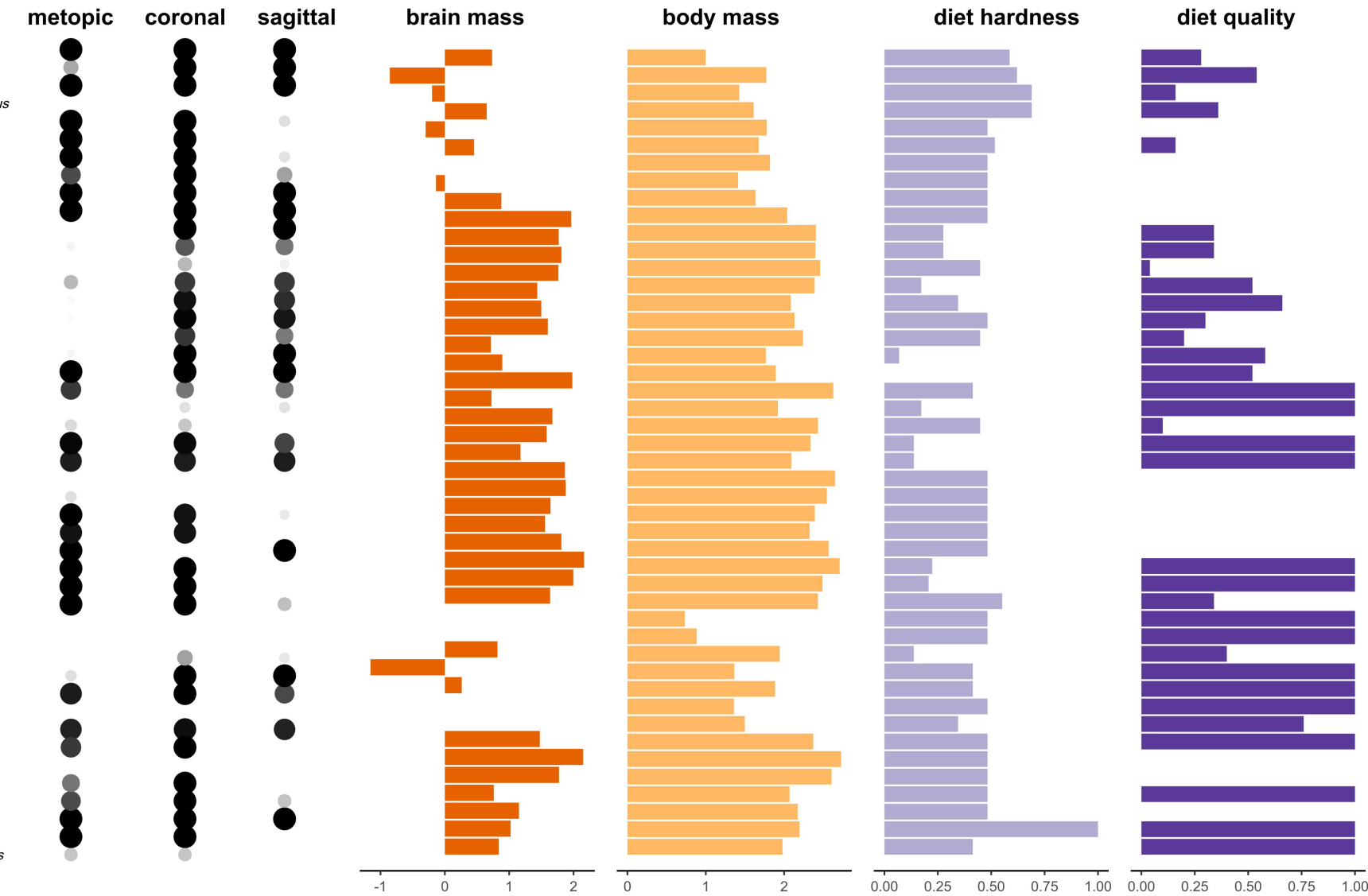



scenarios

AA OPEN SUTURE AA CLOSED SUTURE AA SUBSTITUTION

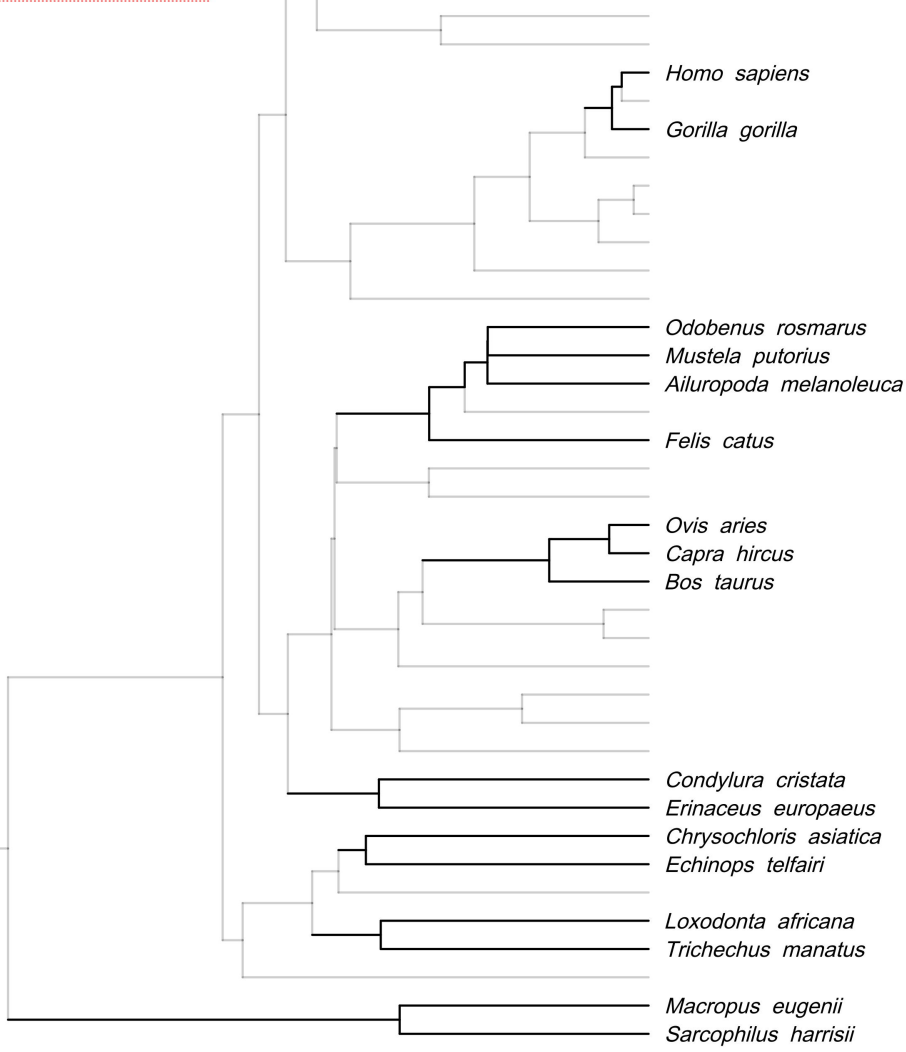

scenario 1

fixed $\rightarrow$ fixed

scenario 2

fixed $\rightarrow$ variable

scenario 3

variable $\rightarrow$ fixed

\section{phenotypic groups}

\section{metopic suture}

MLHSPNKKQPQ

MLHSPHKQPQ

MLHSPHKQPQ

MLHSPN:KQPQ

MLHSPHKQPQ

MLHSPNKKQPQ

\section{coronal suture}

NHKCGANFLQ

NHKCGPNFLQ

NHKCGANFLQ NHKCGENFLQ

NHKCGANFLQ NHKCGKNFLQ sagittal suture

\section{EDCKQALAFK}

EDCKKALAFK

EDCKLALAFK

EDCKKALAFK 
